\title{
Pembangkit Tegangan Tinggi Frekuensi Tinggi Kumparan Tesla untuk Generator Ozon
}

\author{
Annita Lubis ${ }^{1}$, Sukardi ${ }^{2}$ \\ 1,2Universitas Negeri Padang \\ Jl. Prof Dr. Hamka Air Tawar, Padang, Indonesia \\ annitadua@gmail.com¹ ${ }^{1}$ sukardiunp@ft.unp.ac.id ${ }^{2}$,
}

\begin{abstract}
Ozone is a compound that has many benefits and plays a role in the development of science and technology. Ozone can be used for sterilization, removing color, deodorizing, and breaking down organic compounds. Ozone can be generated by several methods, one of which is through the plasma discharge process. This method requires high voltage electricity to break down oxygen molecules into oxygen ions which will form ozone. High voltage can be generated by using the DC tesla coil. The advantages of DC tesla coil Compared to other high voltage generators, it can generate high voltage with a simple system, only requires a small space, and does not cost a lot of money. The output of this research is ozone gas which can be used to neutralize colored liquids. Ozone can replace the use of chlorine to neutralize the color of the liquid is more environmentally friendly because the residual ozone will return to an oxygen compound at a certain time. Based on experiments conducted, the concentration of ozone produced is influenced by several factors, including the length of time of ozonation, oxygen flow rate and high voltage.
\end{abstract}

Keywords - High voltage, Tesla coil, Discharge plasma, Ozone

\begin{abstract}
Abstrak - Ozon adalah senyawa yang memiliki banyak manfaat dan peranan dalam perkembangan ilmu pengetahuan dan teknologi. Ozon dapat dimanfaatkan untuk sterilisasi, menghilangkan warna, menghilangkan bau, dan menguraikan senyawa organik. Ozon dapat dibangkitkan dengan beberapa metode salah satunya melalui proses lucutan plasma (plasma discharge. Metode ini membutuhkan listrik tegangan tinggi untuk memecah molekul oksigen menjadi ion-ion oksigen yang akan membentuk ozon. Tegangan tinggi dapat dibangkitkan dengan menggunakan DC tesla coil. Keunggulan DC tesla koil dibandingkan pembangkit tegangan tinggi lainnya adalah dapat membangkitkan tegangan tinggi dengan sistem yang sederhana, hanya membutuhkan ruang yang kecil, dan tidak menghabiskan banyak biaya. Output dari penelitian ini berupa gas ozon yang dapat digunakan untuk menetralkan warna cairan berwarna. Ozon dapat menggantikan penggunaan klorin untuk menetralkan warna cairan dengan lebih ramah lingkungan karena residu ozon akan kembali menjadi senyawa oksigen pada rentang waktu tertentu. Berdasarkan percobaan yang dilakukan konsentrasi ozon yang dihasilkan dipengaruhi oleh beberapa faktor, diantaranya lama waktu ozonisasi, laju alir oksigen, dan tegangan tinggi.
\end{abstract}

Kata kunci- Tegangan tinggi, Kumparan tesla, Lucutan plasma, Ozon

\section{Pendahuluan}

Perkembangan teknologi sangat diperlukan untuk memenuhi kebutuhan manusia dari waktu kewaktu. Semakin banyaknya industri yang dikembangkan untuk memenuhi kebutuhan tersebut juga akan meningkatkan tingkat pencemaran lingkungan. Salah satu dampak yang paling terlihat adalah mencemaran limbah terhadap air yang akan berdampak pada krisis air bersih[1]. Pengolahan air atau sterilisasi menggunakan ozon dapat dilakukan untuk memecahkan masalah tersebut. Penggunaan ozon untuk proses sterilisasi sangat baik karna merupakan pengoksidasi yang kuat dan dapat menggantikan klorin sehingga dapat digunakan untuk sterilisasi air limbah, disinfektan, pembunuh kuman dan penghilang bau [2]. Keunggulan penggunaan ozon dibandingkan disinfektan lain adalah struktur molekulnya yang tidak stabil karena terdiri dari tiga atom oksisen $\left(\mathrm{O}^{3}\right)$ sehingga cepat mengurai dan akan berubah menjadi oksigen $\left(\mathrm{O}^{2}\right)$ sehingga dapat diterima baik lingkungan [3].

\section{A. Generator Ozon}

Ozon dapat diproduksi dengan menggunakan metode lucutan plasma atau corona discharge yaitu dengan melewatkan oksigen $\left(\mathrm{O}^{2}\right)$ pada dua elektroda yang dialiri tegangan tinggi sehingga terjadi lucutan plasma diantaranya[4]. Ketika oksigen melewati area tegangan tinggi akan mengalami ionisasi yaitu terlepasnya atom atau molekul dari ikatannya menjadi ion-ion oksigen $\left(\mathrm{O}^{*}\right)$ yang akan berikatan dengan molekul yang tidak terionisasi menjadi ozon $\left(\mathrm{O}^{3}\right)$.

Generator Ozon yang digunakan menggunakan proses tumbukan dengan melewatkan gas oksigen $\left(\mathrm{O}^{2}\right)$ pada daerah yang dikenai tegangan tinggi. Molekul oksigen $\left(\mathrm{O}^{2}\right)$ yang dikenai tegangan tinggi ini akan mengalami ionisasi yaitu proses terlepasnya suatu atom atau molekul dari ikatannya menjadi ion-ion oksigen $\left(0^{*}\right)$. Ion oksigen yang berikatan dengan molekul oksigen akan membantuk ozon $\left(\mathrm{O}^{3}\right)$. Metode yang digunakan yaitu lucutan plasma atau 
plasma discharge. Generator ozon terdiri dari tiga bagian yaitu elektroda positif yang akan diberi tegangan tinggi, elektroda negatif (ground) dan tabung lucutan plasma yang berupa selang kaca yang dilubangi pada dua sisinya untuk masukan electroda dan kedua ujungnya sebagai tempat keluar masuknya gas[5].

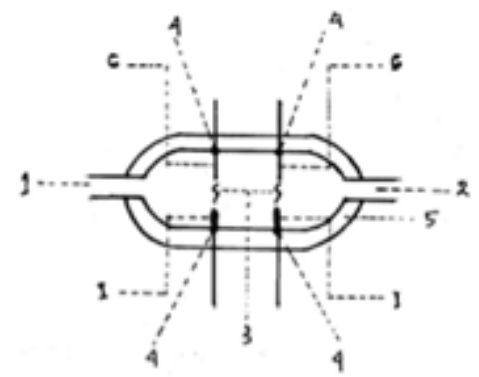

Gambar 1. Skema Reaktor ozon; (1) Gas masuk, (2) Gas keluar, (G) elektroda negatif, (I) elektroda positif, (3) lucutan listrik, (4) Lubang tempat masuknya elektroda, (5) Aluminium foil [5]

\section{B. Kumparan Tesla}

Terkait dengan kebutuhan tegangan tinggi, pembangkit tegangan tinggi yang ada sekarang ini masih dalam sistem yang besar, susah dalam pengoperasian, serta memerlukan biaya yang mahal dalam pembangkitannya. Selain itu pembangkit tegangan tinggi AC pada umumnya memiliki frekuensi yang rendah yaitu $50 \mathrm{~Hz}$. Sedangkan untuk membangkitkan plasma diperlukan tegangan tinggi dengan frekuensi tinggi[6]. Untuk itu dibutuhkan sebuah alat pembangkit tegangan tinggi yang memiliki dimensi tidak terlalu besar, mudah dioperasikan, dan tidak memakan biaya yang mahal. Salah satu solusi dari permasalahan tersebut yaitu dengan menggunakan kumparan tesla yang akan menghasilkan tegangan tinggi frekuensi tinggi. Pembangkit tegangan tinggi khususnya tegangan tinggi frekuensi tinggi dapat dibuat dengan teknik sederhana dan dengan biaya yang cukup murah yaitu dengan menggunakan kumparan tesla[7]

Banyak pengembangan yang dilakukan pada tesla koil konvensional untuk meningkatkan efisiensi dan penggunaan perangkat. Salah satu bentuk pengembangan tersebut yaitu mengubah suplai dari rangkaian menjadi tegangan DC. Perubahan suplai akan mengakibatkan perubahan pada rangkaiannya[8].

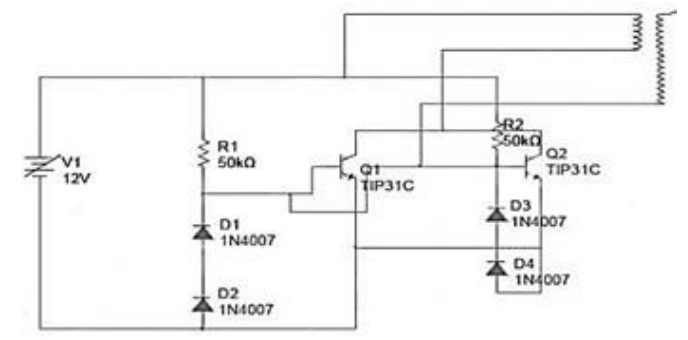

Gambar 2. Rangkaian DC Tesla coil [8]
Prinsip kerjanya cukup sederhana. Ketika catu daya 12 VDC dinyalakan, maka arus positif mengalir pada rangkaian. Karena basis dan kolektor dihubungkan ke ujung positif, maka terjadi reverse bias pada transistor yang menyebabkan transistor tetap mati. Karena resistansi yang sangat besar dihasilkan melalui diode reverse bias, arus masuk ke persimpangan basis transistor. Ketika saklar terbuka, maka arus akan dengan bebas mengalir dari kumparan primer melewati kolektor dan menuju emitor transistor. Selanjutnya diode akan mengalami forward bias dan melewatkan arus dari emitor kembali ke basis. Maka arus akan terus mengalir pada kumparan primer setelah transistor dihidupkan. Selanjutnya pada kumparan primer terbentuk medan magnet yang menghubungkannya dengan kumparan sekunder.

Ketika kumparan sekunder dan primer terhubung, elektron seharusnya mulai mengalir ke bagian atas kumparan sekunder, namun karna bagian atas kumparan yang terhubung dengan udara memiliki resistansi yang sangat tinggi, sedangkan sifat electron selalu bergerak ke jalur yang tidak resistan membuat muatan positif terus berkembang pada bagian atas kumparan sekunder. Semakin kuat hubungan kedua kumparan, maka semakin banyak muatan positif yang terbentuk sehingga bagian atas kumparan sekunder semakin kuat menarik electron yang ada dikumparan. Hal tersebut mengakibatkan aliran electron yang sangat tinggi secara tiba-tiba dari bagian bawah koil ke bagian atas secara tiba-tiba.

Saat elektron mencapai terminal positif atau netral, mereka akan mematahkan hambatan udara dan menghasilkan percikan cahaya terang yang bervoltase tinggi. Bumi akan berperan sebagai ground yang yang terhubung pada bagian bawah kumparan yang terbuka. Besarnya luas permukaan bumi dapat menyerap banyaknya arus dan juga cahaya yang dihasilkan. Tidak hanya bumi, benda logam yang didekatkan pada bagian atas kumparan akan dianggap sebagai ground karna lebih positif daripada kumparan sekunder. Panjang percikan dipengaruhi oleh tegangan input, panjang kumparan, dll.

\section{Metode}

Koil tesla DC memecahkan masalah dengan lebih baik karena dapat menyetel otomatis. Trafo besar untuk memberikan suplai AC pada Kumparan tesla AC diganti dengan baterai kecil. Celah percikan yang membutuhkan sekitar $3000 \mathrm{~V}$ sebagai pemicu dapat diganti dengan transistor. Hal lain yang dihilangkan adalah beban atas. Karena perangkat memberikan percikan api yang panjang, beban atas dihilangkan. Masalah utama seperti bulkiness, tegangan tinggi dan arus, portabilitas diselesaikan menggunakan model ini. Pada penelitian ini coil kumparan tesla lilitan primer dan sekunder diganti dengan modul tesla coil yang dapat membangkitkan sampai $4000 \mathrm{~V}$ tegangan tinggi. 


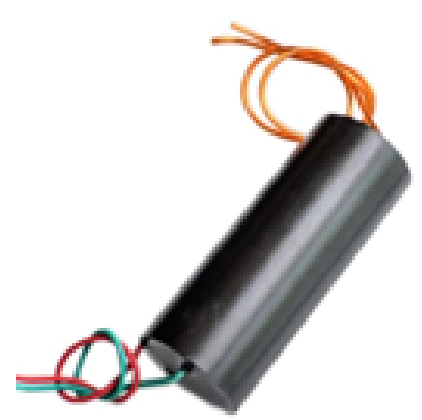

Gambar 3. Tesla Coil Module Step Up 3-6V DC ke 4000V High Voltage

A. Blog Diagram

Pada tugas akhir "pembangkitan tegangan tinggi frekuensi tinggi kumparan tesla untuk reaktor ozon" terdiri dari beberapa bagian, sepert Gambar 4 dibawah ini.



Gambar 4. Blog diagram system keseluruhan

B. Flowchart

Untuk mempermudah kita dalam merancang suatu alat, maka kita harus mengetahui prinsip kerja dari alat yang ingin kita buat. Untuk lebih mengetahui bagaimana sistem kerjanya dapat dilihat pada flowchart.

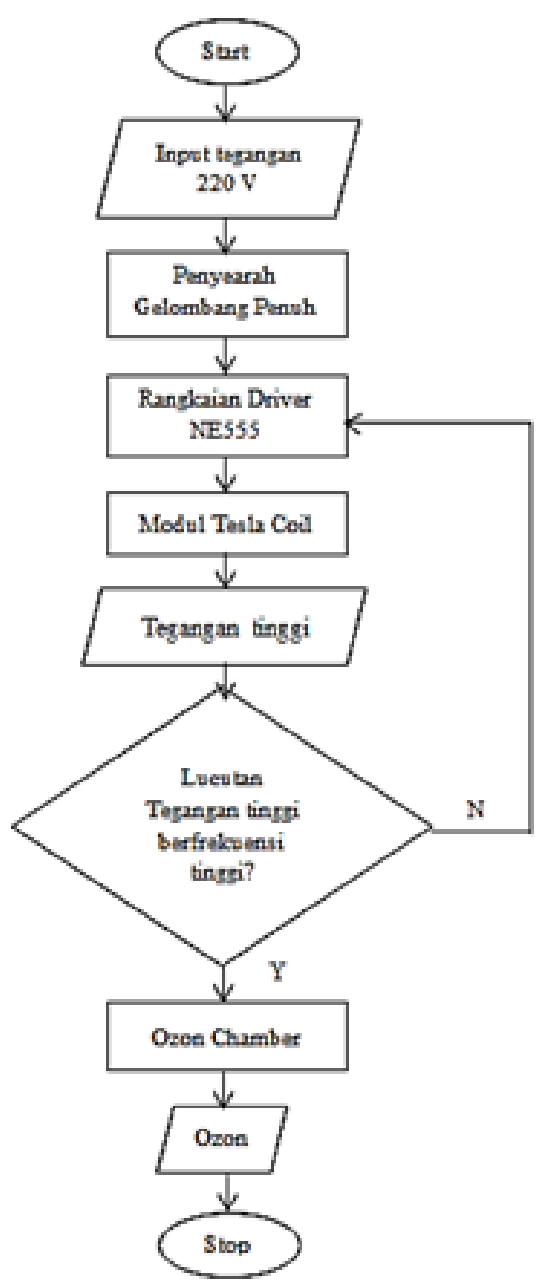

Gambar 5. Diagram Alir (Flowchart) Perancangan Alat

C. Perancangan Rangkaian

1) Rangkaian Penyearah

Rangkaian penyearah yang digunakan pada penelitian ini adalah penyearah gelombang penuh dengan empat diode dan beberapa kapasitor untuk mengurangi riak gelombang DC yang dihasilkan. Output dari penyearah dilanjutkan pada rangkaian regulator LM2596. Regulator LM2596 lebih baik digunakan dibandingkan LM7805 untuk power suplay switching dan untuk beban arus yang cukup tinggi.

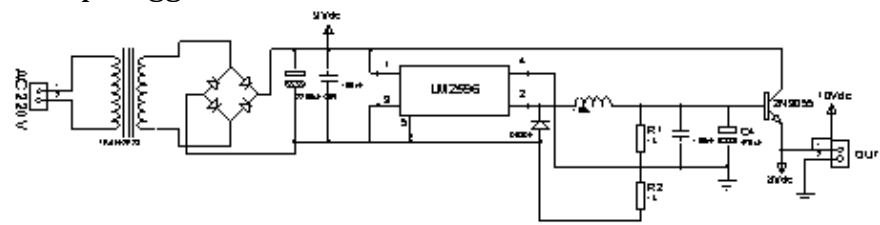

Gambar 6. Rangkaian penyearah gelombag penuh

2) Rangkaian Driver NE555

Driver tersusun oleh oscillator dan IC atau transistor switching yang akan memicu modul tesla coil. Oscillator, dirancang menggunakan IC 555 dengan mode operasi 
astable dan gelombang kotak yang dihasilkan pada frekuensi tertentu dengan memutar kenop potensiometer. Output dari rangkaian ini yaitu pada pin 3 yang diberi penguatan dengan transistor BD139.

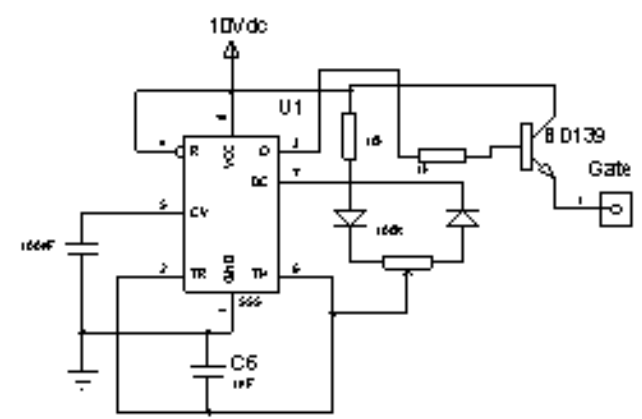

Gambar 7. Rangkaian Driver NE555

Untuk menghitung nilai frekuensinya dapat dicari dengan persamaan dibawah ini

$\mathrm{f}=\frac{1.44}{(\mathrm{R} 1+2 \mathrm{R} 2) \mathrm{C} 1}$

Frekuensi bisa terus bertambah dengan memutar potensio sehingga nilai R2 berkurang.

\section{3) Rangkaian MOSFET IRFP460}

Rangkaian MOSFET yang dimaksud yaitu memparalelkan dua buah MOSFET IRFP460 seperti gambar 8. Input diberikan berupa output dari rangkaian driver NE555. Pada rangkaian ini mosfet berperan sebagai saklar yang menghubungkan bagian bawah kumparan primer ke ground.

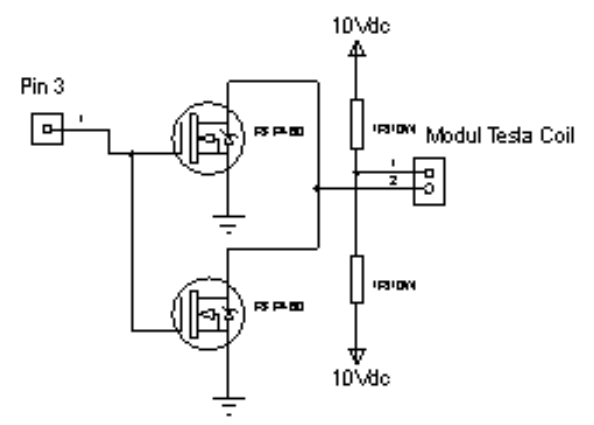

Gambar 8. Rangkaian MOSFET IRFP460

D. Perancangan Mekanik

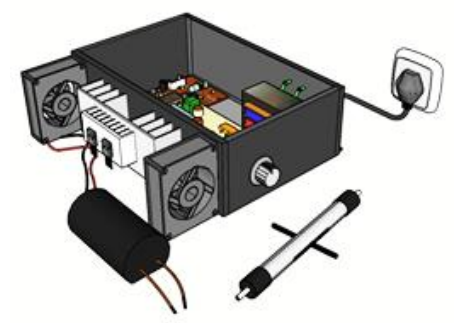

Gambar 9. Perancangan keseluruhan mekanik

\section{HASIL DAN PEMBAHASAN}

Tujuan yang hendak pada penelitian ini adalah menghasilkan ozon yang bermanfaat untuk proses sterilisasi dengan menggunakan metode lucutan plasma yang memanfaatkan loncatan listrik dari pembangkit tegangan tinggi modul DC tesla coil. Konsentrasi ozon diukur berdasarkan pengaruhnya terhadap cairan berwarna berdasarkan beberapa faktor yang mempengaruhinya diantaranya waktu, laju alir oksigen, dan frekuensi tegangan tinggi.

\section{A. Pengujian Mekanik Modul Tesla Coil}

Pengujian modul tesla coil adalah untuk melihat adanya loncatan listrik bertegangan tinggi dari kedua elektroda positif dan negatifnya yang akan digunakan sebagai input pada generator ozon.

Tahapan pengujian adalah sebagai berikut:

- Sambungkan kabel penghantar dengan sumber tegangan PLN $220 \mathrm{~V}$.

- Atur jarak kedua elektroda modul tesla coil untuk melihat jarak terjauh yang dapat menghasilkan lucutan listrik tegangan tinggi.

- Atur frekuensi lucutan listtrik dengan memutar potensio pada rangkaian driver NE555.

Jika semua bekerja dengan baik, maka dapat diketahui panjang loncatan listrik yang dihasilkan dan dapat mengatur frekuensinya.

1) Pengukuran Panjang Loncatan Listrik

Tabel 1. Hasil Pengukuran Panjang Loncatan Listrik

\begin{tabular}{ccc}
\hline No. & Titik Pengukuran & Hasil Pengukuran \\
\hline 1 & $\begin{array}{c}\text { Panjang loncatan } \\
\text { listrik modul tesla coil }\end{array}$ & $1 \mathrm{~cm}$ \\
\hline
\end{tabular}

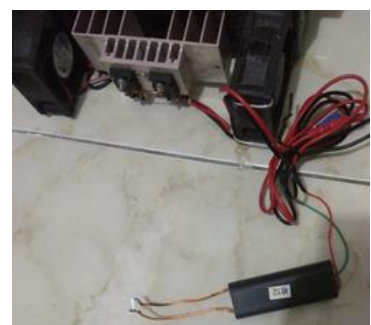

Gambar 10. Pengujian panjang loncatan listrik

Loncatan listrik yang diperoleh bersifat konstan yang berarti nilai tegangan outputnya bernilai konstan. Hal tersebut disebabkan oleh nilai input yang diberikan pada sisi primer modul tesla coil bernilai konstan 10 VDC. Panjang loncatan listrik diperlukan untuk penyettingan jarak elektroda-elektroda pada generator ozon. 
2) Pengujian Rangkaian Penyearah

Tabel 2. Hasil Pengukuran Rangkaian Konverter

\begin{tabular}{ccc}
\hline No. & Titik Pengukuran & Hasil Pengukuran \\
\hline 1. & Output converter & $6.5 \mathrm{Vdc}$ \\
\hline
\end{tabular}

Input yang diberikan yaitu 7.5 Vac. Terjadi penurunan tegangan dibagian output dikarenakan pengaruh penggunaan kapasitor untuk mengurangi riak gelombang tegangan. Selain itu regulator $\operatorname{lm} 2596$ digunalan agar arus yang dihasilkan mencapai 3 A juga akan mempengaruhi tegangan output menjadi semakin kecil.

\section{B. Pengukuran Frekuensi Tinggi yang Dihasilkan}

Pengukuran dilakukan dengan melakukan pembacaan bentuk gelombang dari output rangkaian driver NE555 (pin 3) menggunakan oscilloscope Aditeg OS-640 $40 \mathrm{MHz}$. skala periode gelombang diatur $5 \mathrm{mS} / \mathrm{DIV}$. Potensio akan diputar dengan presentasi putaran 0\%, 25\%, 50\%, $75 \%$ dan $100 \%$

\section{Tabel 3 Hasil Perubahan Warna Cairan terhadap Waktu}

\begin{tabular}{ll|l}
\hline No. & $\begin{array}{c}\text { Putaran } \\
\text { Potensio }\end{array}$ & $\begin{array}{c}\text { Gambar } \\
\text { Gelombang }\end{array}$ \\
\hline 1. & $0 \%$ & \\
& & \\
\hline 2. & $25 \%$ & \\
\hline & & \\
\hline 3. & $50 \%$ & \\
\hline & & \\
\hline & & \\
\hline & & \\
\hline & & \\
\hline & & \\
\hline
\end{tabular}

Untuk perhitungan frekuensi yang dihasilkan juga dapat diperoleh menggunakan rumus (1).

$$
\begin{array}{ll}
\text { Diketahui } & : \mathrm{R} 1=10 \mathrm{~K} \Omega \\
& \mathrm{C} 1=1 \mathrm{nF} \\
\text { Ditanya } & : \mathrm{f} ?
\end{array}
$$

$$
\mathrm{f}=\frac{1.44}{(\mathrm{R} 1+2 \mathrm{R} 2) \mathrm{C} 1}
$$

- Putaran $0 \%(\mathrm{R} 2=0 \Omega)$

$$
\begin{aligned}
\mathrm{f} & =\frac{1.44}{(10 \mathrm{k}+2.0) 10^{\wedge}-9} \\
& =144 \mathrm{KHz}
\end{aligned}
$$

- Putaran $75 \%(\mathrm{R} 2=75 \mathrm{~K} \Omega)$

$$
\begin{aligned}
\mathrm{f} & =\frac{1.44}{(10 \mathrm{k}+2.75) 10^{\wedge}-9} \\
& =9 \mathrm{KHz}
\end{aligned}
$$

- $\quad$ Putaran $25 \%(\mathrm{R} 2=25 \mathrm{~K} \Omega)$

$$
\begin{aligned}
\mathrm{f} & =\frac{1.44}{(10 \mathrm{k}+2.25 \mathrm{~K}) 10^{\wedge}-9} \\
& =24 \mathrm{KHz}
\end{aligned}
$$

- Putaran $100 \%(\mathrm{R} 2=$ $100 \mathrm{~K} \Omega$ )

$$
\begin{aligned}
\mathrm{f} & =\frac{1.44}{(10 \mathrm{k}+2.100) 10^{\wedge}-9} \\
& =6857 \mathrm{~Hz}
\end{aligned}
$$

- Putaran $50 \%(\mathrm{R} 2=50 \mathrm{~K} \Omega)$

$$
\begin{aligned}
\mathrm{f} & =\frac{1.44}{(10 \mathrm{k}+2.50) 10^{\wedge}-9} \\
& =13 \mathrm{KHz}
\end{aligned}
$$

Berdasarkan gambar gelombang dan hasil pengukuran dapat kita lihat bahwa frkuensi tertinggi yang diperoleh adalah pada saat R2 bernilai 0 .

\section{Pengukuran Konsentrasi Ozon}

Pengukuran terhadap konsentrasi ozon dilakukan dengan mengamati perubahan warna cairan yang dipengaruhi ozon output dari generator ozon. Cairan berwarna yang digunakan yaitu berwarna merah campuran minuman Fanta dan air, dan berwarna biru campuran tinta bitu dan air. Percobaan dilakukan berdasarkan faktor-faktor yang mempengaruhi output ozon yaitu waktu, laju alir/tekanan oksigen, dan frekuensi.

Langkah-langkah percobaanya yaitu:

- Hubungkan elektroda modul tesla coil pada generator ozon.

- Salah satu ujung tabung dihubungkan ke tabung oksigen menggunakan selang silicon, ujung satunya sebagai output dipasang selang silikon dan dimasukkan pada gelas yang telah barisi cairan berwarna untuk percobaan.

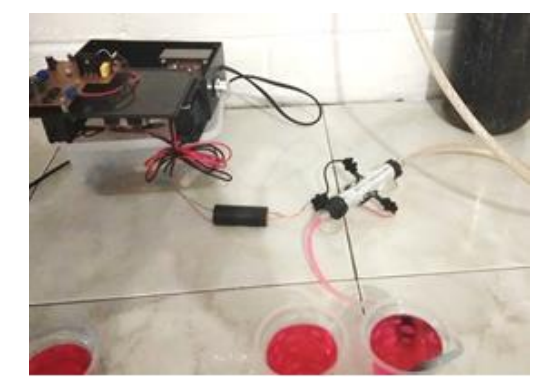

Gambar 11. Rangkaian percobaan

Percobaan akan dilakukan menjadi tiga bagian berdasarkan factor-faktor yang mempengaruhi konsentrasi ozon yang dihasilkan, diantaranya: 
1) Pengujian pengaruh waktu terhadap konsentrasi ozon.

Pengujian dilakukan dengan memasukkan gas ozon hasil dari generator ozon ke dalam gelas yang berisi cairan berwarna merah. Hasil dari pengujian dapat dilihat seperti pada tabel 4.

\section{Tabel 4 Hasil Perubahan Warna Cairan terhadap Waktu}

\begin{tabular}{|c|c|c|}
\hline No. & Waktu & Hasil Pengukuran \\
\hline 1. & 0 menit & \\
\hline 2. & 2 menit & \\
\hline 3. & 4 menit & \\
\hline 4. & 8 menit & \\
\hline 5. & 10 menit & . \\
\hline
\end{tabular}

Dari tabel 3 terlihat bahwa semakin lama cairan diberi gas dari reaktor ozon maka kepekatan warnanya akan semakin berkurang. Hal ini terjadi karena ketika ozon bereaksi dengan air maka ozon akan membentuk peroxide (HO2) sesuai dengan reaksi sebagai berikut.

$\mathrm{O}^{3}+\mathrm{H}_{2} \mathrm{O} \rightarrow \mathrm{HO}_{3}^{+}+\mathrm{OH}^{-}$

$\mathrm{HO}_{3}+\mathrm{OH}^{-} \leftrightarrow 2 \mathrm{HO}_{2}$

$\mathrm{HO}_{2}^{-}+\mathrm{O}_{3} \rightarrow \mathrm{OH}^{-}+2 \mathrm{O}_{2}$

Pada waktu yang sama, ozon yang dihasilkan oleh reaktor akan bereaksi dengan peroxide membentuk radikal $\mathrm{OH}$ - dan gas oksigen (02). Radikal peroxide yang terbentuk selama reaksi akan berubah menjadi $\mathrm{OH}$ - dan menguraikan ikatan warna pada cairan. Sehingga air yang diberi ozon warnanya akan memudar
2) Pengujian pengauh laju alir oksigen terhadap konsentrasi ozon.

Pengujian yang dilakukan dengan terlebih dahulu menyiapkan tiga buah gelas yang berukuran sama yang diisi cairan penguji berwarna merah. Kemudian dari masing-masing gelas akan diberi udara keluaran dari reaktor ozon dengan variasi tekanan oksigen yang berbeda-beda.



\section{Gambar 12. Sebelum pengujian pengaruh laju alir oksigen terhadap konsentrasi ozon}

Masing-masing gelas akan diberi udara keluaran dari reaktor ozon dengan variasi tekanan yang berbeda yaitu 16 Lbs/in², 18 Lbs/in², dan 20 Lbs/in², selama 6 menit. Dari hasil percobaan didapatkan gambar yang dapat dilihat pada tabel 5 .

\section{Tabel 5. Hasil Perubahan Warna Cairan terhadap Tekanan Oksigen}

\begin{tabular}{ccc}
\hline No. & Tekanan & Hasil Pengukuran \\
\hline 1. & $16 \mathrm{Lbs} / \mathrm{in}^{2}$ & \\
\hline 2. & $18 \mathrm{Lbs} / \mathrm{in}^{2}$ & \\
& \\
& \\
\hline 3. & 20 Lbs/in ${ }^{2}$ \\
\hline
\end{tabular}

Berdasarkan azas Bernoulli, di dalam fluida yang mengalir dengan kecepatan tinggi akan diperoleh tekanan yang lebih kecil. Sebaliknya, pada kecepatan yang rendah akan diperoleh tekanan yang lebih tinggi. Jadi, tekanan di dalam fluida berbanding terbalik dengan kecepatan alirannya. Dari hasil percobaan yang dilakukan terlihat bahwa semakin tinggi tekanan oksigen yang diberikan maka semakin banyak oksigen yang dihasilkan dalam jangka waktu yang sama. Dengan demikian konsentrasi ozon yang dihasilkan juga berbanding terbalik dengan kecepatan aliran oksigen yang diberikan. Hal ini berkaitan dengan densitas (rapat molekul atau muatan) yang ada di 
dalam reaktor. Ketika diberikan debit udara yang lebih kecil, maka di densitas molekul menjadi lebih kecil sehingga jarak jalan bebas rata-rata masing-masing molekul untuk dapat bergerak menjadi lebih panjang. Hal ini menyebabkan transfer energi ketika terjadi tumbukan menjadi lebih efektif apabila dibandingkan dengan densitas yang lebih tinggi.

3) Pengujian Pengaruh Frekuensi Terhadap Konsentrasi Ozon

Pengujian yang dilakukan dengan terlebih dahulu menyiapkan empat buah gelas yang berukuran sama berisi cairan berwarna biru deperti yang terlihat pada gambar dibawah ini.



\section{Gambar 13. Sebelum pengujian pengaruh frekuensi terhadap konsentrasi ozon}

masing-masing gelas akan diberi udara keluaran dari reaktor ozon dengan variasi nilai frekuensi yang dengan memutar potensio dengan persentasi $0 \%, 25 \%, 50 \%$, dan $75 \%$ dalam waktu 5 menit. Dari hasil percobaan yang diperoleh dapat dilihat pada tabel 6 .

\section{Tabel 6 . Hasil Perubahan Warna Cairan terhadap Frekuensi}

\begin{tabular}{lcc}
\hline No. & $\begin{array}{c}\text { \% Putaran } \\
\text { potensio }\end{array}$ & Hasil Pengukuran \\
\hline 1. & $0 \%$ & \\
\hline 2. & $25 \%$ & \\
\hline 3. & \\
\hline 4. & \\
\hline & \\
\hline & \\
\hline
\end{tabular}

Dari percobaan yang dilakukan terlihat bahwa warna pada cairan yang telah diberi ozon dengan menerapkan frekuensi yang berbeda didapatkan hasil yang sama, yang berarti frekuensi tegangan tinggi yang diberikan tidak mempengaruhi konsentrasi ozon yang dihasilkan. Berbeda dengan penelitian yang dilakukan sebelumnya oleh Johanes Nugroho Adhi Prakosa [9] dimana frekuensi osilasi mempengaruhi konsentrasi ozon yang disebabkan oleh nilai frekuensi osilasi akan mempengaruhi output tegangan converter flyback sebagai sumber tegangan tinggi. Jadi yang mempengaruhi konsentrasi ozonnya adalah nilai tegangan tinggi yang digunakan, bukan frekuensi osilasinya.

\section{PenutuP}

Berdasarkan hasil percobaan konsentrasi ozon yang telah dilakukan, dapat ditarik beberapa kesimpulan bahwa pembangkit tegangan tinggi dapat dibuat dalam bentuk sederhana dan dengan biaya yang terbilang murah menggunakan metode kumparan tesla yang dapat digunakan untuk memecah molekul oksigen dan membentuk ozon. Faktor-faktor yang mempengaruhi konsentrasi ozon yang dihasilkan diantaranya waktu, laju alir oksigen dan tegangan.

Pengaruh waktu terhadap konsentrasi ozon yaitu semakin lama waktu ozonisasi yang dilakukan maka semakin tinggi konsentrasi ozon yang dihasilkan. Pengaruh laju alir oksigen terhadap konsentrasi ozon adalah berbanding terbalik dimana semakin tinggi laju alir yang diberikan, maka konsentrasi ozon yang dihasilkan akan berkurang karena proses ozonisasi pada generator ozon akan lebih cepat jika laju alirnya tinggi. Pengaruh tegangan tinggi terhadap konsentrasi ozon yaitu semakin tinggi tegangan tinggi yang digunakan maka semakin tinggi konsentrasi ozon yang dihasilkan.

\section{REFERENSI}

[1] Z. Muhlisin, wulandary Oktiyana, and M. Nur, 'Aplikasi Plasma Lucutan Berpenghalang Dielektrik pada Peningkatan Kualitas Air dengan Mengalirkan Air secara Langsung dalam Rraktor Berkonfigurasi Elektroda SpiralSilinder', Berk. Fis. Univ. Diponegoro Semarang, vol. 12, pp. 99-106, Jul. 2009.

[2] S. Seke, M. Nur, and T. A. Winarni, 'Produksi Ozon dalam Reaktor Dielectrik Barrier Discharge Plasma (DBDP) Terkait Panjang Reaktor dan Laju Alir Udara Serta Pemanfaatannya Untuk Menjaga Kualitas Asam Amino Ikan', Berk. Fis. Univ. Diponegoro Semarang, vol. 17, No 1, pp. 25-32, Jan. 2014.

[3] B. Yusuf, 'Aplikasi Pembangkit Tegangan Tinggi Impuls untuk Pembuatan Reaktor Ozon', Univ. Diponegoro Semarang Indones., 2008.

[4] W. Suwarno, D. Andrio, and J. Asmura, 'Pengukuran Produktivitas Ozon sebagai Oksidator Senyawa Organik Pencemar', JOM FTEKNIK Univ. Riau Pekan Baru, vol. 4 no 2, Oktober 2017.

[5] R. T. Tjahjanto, S. Wardhani, and U. Anggraini, 'Studi Sintesis Ozon dengan Metode Lucutan Plasma', Nat. B Univ. Brawijaya Malang, vol. 1 no 3, pp. 279-286, Apr. 2012. 
[6] R. Heryanto, M. Facta, and M. A. R, 'Perancangan Inverter Half Bridge sebagai Catu Daya Tegangan Tinggi AC Frekuensi Tinggi dengan Beban Kumparan Tesla dan Dielectric Barrier Discharge Chamber', Transient, vol. 4 no 1 , pp. 114-121, 2015.

[7] A. Habibi, 'Pembangkit Tegangan Tinggi Bolak - Balik Frekuensi Tinggi Menggunakan Kumparan Tesla', Univ. Diponegoro Semarang Indones., 2007.

[8] P. Manchanda, 'DC Tesla Coil Construction and Applications', Ijraset, vol. 4, no. VII, pp. 579-584, Jul. 2016.

[9] J. N. A. Prakosa, M. Facta, and M. A. Munawar Agus Riyadi, 'Perancangan Pembangkit Tegangan Tinggi Impuls Berbasis Converter Flyback', Transm. Univ. Diponegoro Semarang, vol. 17 no 2, 2015.

[10] S. Abduh, Dasar Pembangkit dan Pengukuran Teknik Tegangan Tinggi, 1st ed. Jakarta: Salemba Teknika, 2001.

[11] B. L. Tobing, Dasar Pembangkitan dan Pengukuran Teknik Tegangan Tinggi, Edisi Ketiga. Jakarta: Erlangga, 2017.

[12] W. Mujahid, 'Perancangan Pembangkit Tegangan Tinggi AC Frequensi Tinggi Dengan Kumparan Tesla Menggunakan Inverter Jenis Push-Pull', Jan. 2011.

[13] A. B. Setiawan, M. Facta, and A. Syakur, 'Perancangan Pembangkit Tegangan Tinggi AC Frekuensi Tinggi Menggunakan Kumparan Tesla dengan Rangkaian Resonansi Seri', Transient Univ. Diponegoro Semarang, vol. 3 no 2, pp. 174-180, Jun. 2014.

\section{Biodata Penulis}

Annita Lubis, lahir di Tempurung, 18 Juni 1998. Menyelesaikan studi DIV Teknik Elektro Industri pada Jurusan Teknik Elektro Fakultas Teknik Universitas Negeri Padang. ${ }^{[1]}$

Dr.Sukardi, M.T, lahir di Semerap Kerinci, 10 Mei 1961. menempuh pendidikan di Kerinci sejak SD, SMP dan SMA, melanjutkan kuliah Sarjana (S1) di IKIP Padang Indonesia Jurusan Pendidikan Teknik Eleltro, Magister (S2) Teknik ELektro di Institut Teknologi Bandung, dan Program Doktor (S3) bidang Pendidikan Teknologi dan Kejuruan di Pascasarjana Universitas Negeri Yogyakarta. Saat ini bertugas sebagai Dosen dan menekukni riset bidang Pendidikan Teknologi dan Kejuruan Ketenagalistrikan. ${ }^{[2]}$ 